\title{
Creating Sound Signal Histogram to be Used in Signal Decomposition
}

\author{
Prof. Yousif Eltous ${ }^{1}$, Dr. Jihad Nader ${ }^{2}$, Dr. Mohammad S. Khrisat ${ }^{3}$, \\ Saleh A. Khawatreh ${ }^{4}$, Prof. Ziad Alqadi ${ }^{5}$ \\ Al-Balqa Applied University, Faculty of Engineering Technology, Amman, Jordan ${ }^{1,2,3,5}$ \\ Al-Ahliyya Amman University ${ }^{4}$
}

\begin{abstract}
Digital signals including human speeches are very popular and important digital data due to the large number of computerized applications that required them, some of these applications must have an immediate response generating a response in significantly small time. Digital speech usually has a big size, and to reduce a processing time we have to represent the speech by a unique identifier or classifier called speech features. In this paper research we will study the wavelet packet tree decomposition, and we will introduce a method to calculate speech histogram. This histogram can be used as an input data set to the signal decomposition to fix the levels of decomposition and to fix the number of elements in the approximation or the detailed in a selected level of decomposition.
\end{abstract}

Keywords: Speech Signal, WPT, Histogram, Level, Approximations, Details, Features.

\section{INTRODUCTION}

Digital signals [1-40] such as color digital images [1], [2], [3], [4] and digital speeches are the most important data types circulating among different people and institutions, due to the vital computer applications that need this type of data [5], [6], [7], [8]. Digital signals are used in many important applications that serve all people and institutions, such as in fingerprint recognition [9], [10], [16] systems and facial recognition systems [11], [12], voice or speech recognition to identify specific person.

Digital speech [38], [39]as shown in figure 1 is a set of amplitude values taken in a period of time, the number of amplitudes (samples) depends on the sampling frequency and it is usually represented by a $2 \mathrm{D}$ matrix ( 2 columns for stereo speech) or one column matrix (for mono speech) [40], [41], [42] .

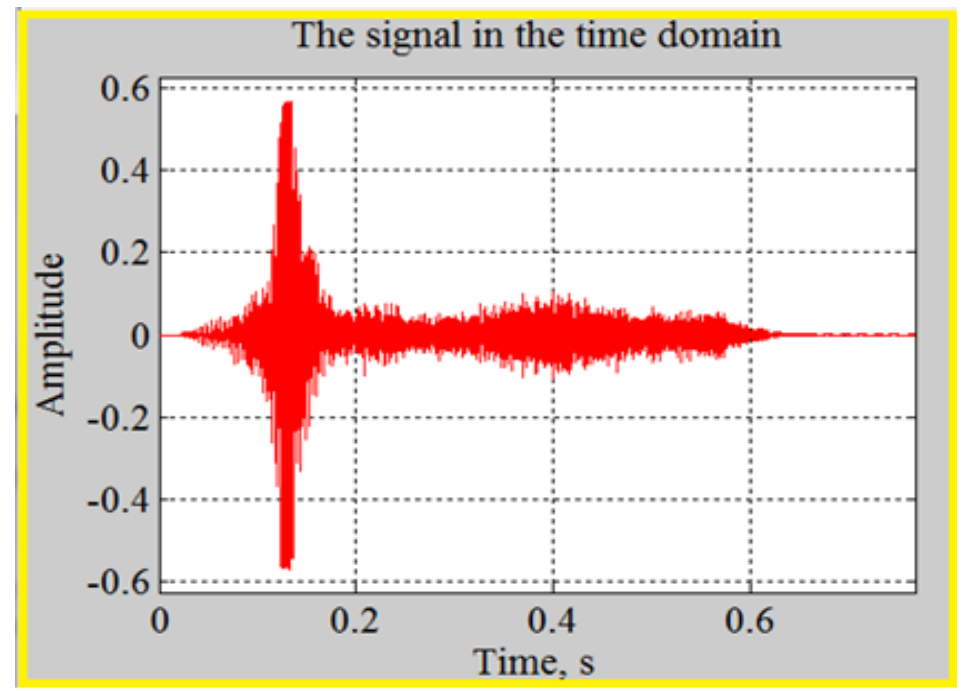

Figure 1: Speech Signal

Digital speeches whether they are mono or stereo usually have a big number of samples, thus they always have big sizes, this leads to extra time for speech matching, table 1 shows used in this paper images information about a recorder human speeches[22], [23].

To make the speech recognition or identification system more efficient we have to replace the speech with a set of values called speech features, this features must be extracted [24], [25], saved to be used later in a recognition system as a classifier or primary key to recognize the speech or to retrieve it. 
Vol. 9, Issue 6, June 2020

Many methods were introduced to extract speech features, some of these methods are based on calculating the features using statistical parameters such sample average and standard deviation [26], [27]. Some methods were based on clustering using C_mean clustering [28], [29], [30] while other methods used the concepts of linear prediction coding to create the image features [31], [32].

Local binary pattern based method also are used to create color image features, these method such as CSLBP and MLP can be efficiently used to create image features, each of these methods provides a number of values which forms the image features [33], [34].

Table 1: Recorded and USED in this paper human speeches

\begin{tabular}{|c|c|c|}
\hline Recorded speech number & Recorded speech & Size(samples) \\
\hline 1 & May God protect Jordanians and all mankind & 220897 \\
\hline 2 & Good morning every one & 132850 \\
\hline 3 & Amman is the capital city of Jordan & 183544 \\
\hline 4 & Petra is a wonderful Jordanian city & 233364 \\
\hline 5 & Aqaba is a Jordanian city located on the red sea & 123010 \\
\hline 6 & Speech decomposition & 145765 \\
\hline 7 & Balqa Applied University & 173071 \\
\hline 8 & Faculty of engineering technology & 148412 \\
\hline 9 & Computer engineering department & 291652 \\
\hline 10 & Creating sound signal histogram to be used in signal decomposition & \\
\hline
\end{tabular}

\section{WAVELET PACKET TREE}

Any digital signal [15], [16], [17], can be decomposed using wavelet packet tree (WPT) [35], [36], [37] methods into approximations (low pass part) and details (high pass parts), the process of signal decomposition can be repeated for a defined number of levels forming a binary tree as shown in figure 2 :

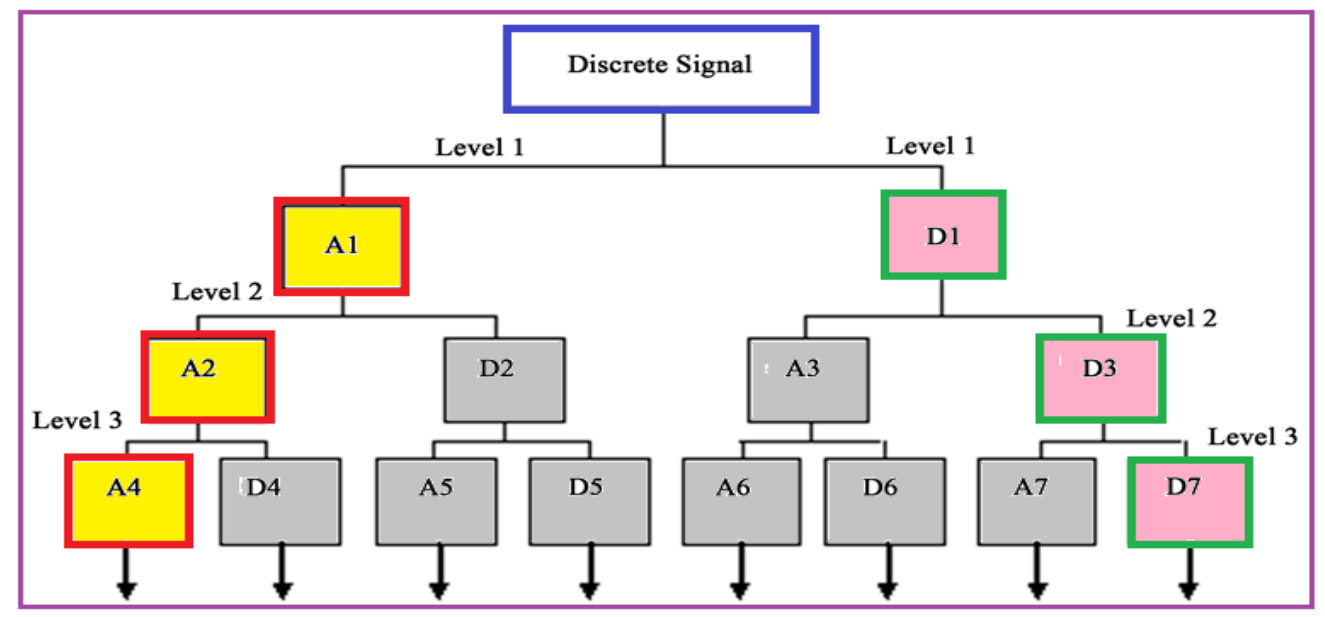

Figure 2: Digital signal decomposition using WPT

The approximations and details at any level can be calculated by Haar scaling function shown in formula 1, while the details at any level can be calculated using Haar wavelet function shown in formula 2:

$$
\begin{aligned}
\mathbf{A}_{j+1, i} & =\frac{\text { even }_{j, i}+o d d_{j, i}}{2} \\
\mathbf{D}_{j+1, i} & =\frac{\text { even }_{j, i}-o d d_{j, i}}{2}
\end{aligned}
$$


Vol. 9, Issue 6, June 2020

Table 2 shows how to decompose a digital signal of 32 values:

Table 2: discrete signal decomposition example

\begin{tabular}{|c|c|c|c|c|c|c|c|c|c|c|c|c|c|c|c|c|}
\hline \multirow{3}{*}{$\begin{array}{l}\text { Lev } \\
\text { el } 1\end{array}$} & 2 & 4 & -2 & \begin{tabular}{|l} 
\\
6
\end{tabular} & \begin{tabular}{|l|}
10 \\
\end{tabular} & 12 & 8 & 7 & -4 & 9 & 3 & 12 & 8 & 0 & 2 & 4 \\
\hline & \multicolumn{8}{|c|}{ Approximation A10 } & \multicolumn{8}{|c|}{ Detail D10 } \\
\hline & 3 & 2 & 11 & 7.5 & 2.5 & 7.5 & 4 & 3 & -1 & -4 & -1 & 0.5 & -6.5 & $-\overline{4.5}$ & 4 & -1 \\
\hline Leve & \multicolumn{4}{|c|}{ A20 } & \multicolumn{4}{|c|}{$\frac{1}{\mathrm{D} 20}$} & \multicolumn{4}{|c|}{ A 21} & \multicolumn{4}{|c|}{ D21 } \\
\hline 2 & 2.5 & 9.25 & 5 & 3.5 & \begin{tabular}{|l|}
- \\
0.5 \\
\end{tabular} & 1.75 & $-\overline{2.5}$ & 0.5 & \begin{tabular}{|l|} 
\\
\end{tabular} & -0.25 & $\begin{array}{l}- \\
5.5 \\
\end{array}$ & 1.5 & 1.5 & $\overline{0.75}$ & -1 & 2.5 \\
\hline Leve & A30 & & D30 & & A31 & & D31 & & A32 & & D32 & & A33 & & D33 & \\
\hline 3 & 5.875 & 4.25 & \begin{tabular}{|l|} 
\\
3.37 \\
5 \\
\end{tabular} & \begin{tabular}{|l|}
0.7 \\
5
\end{tabular} & 0.625 & -1 & $\begin{array}{l} \\
1.125\end{array}$ & -1.5 & $\begin{array}{l}- \\
1.37 \\
5\end{array}$ & -2 & \begin{tabular}{|l|}
- \\
1.12 \\
5
\end{tabular} & -3.5 & 0.375 & 0.75 & 1.125 & -1.75 \\
\hline \begin{tabular}{|c|} 
Leve \\
14
\end{tabular} & $\mathbf{A 4 0}$ & D40 & \begin{tabular}{|l|}
$\mathbf{A 4}$ \\
$\mathbf{1}$
\end{tabular} & \begin{tabular}{|l|} 
D4 \\
1
\end{tabular} & \begin{tabular}{|l|}
$\mathbf{A 4}$ \\
$\mathbf{2}$
\end{tabular} & D42 & $\begin{array}{l}\mathbf{A 4} \\
3\end{array}$ & D43 & \begin{tabular}{|l|} 
A4 \\
$\mathbf{4}$
\end{tabular} & D44 & \begin{tabular}{|l|} 
A44 \\
$\mathbf{5}$
\end{tabular} & D45 & A46 & $\begin{array}{l}\text { D4 } \\
6\end{array}$ & $\begin{array}{l}\text { A4 } \\
7\end{array}$ & D47 \\
\hline & $\begin{array}{l}5.06 \\
25 \\
\end{array}$ & $\begin{array}{l}0.81 \\
25 \\
\end{array}$ & \begin{tabular}{|c|}
-1.8 \\
125
\end{tabular} & \begin{tabular}{|c|}
-2.0 \\
625
\end{tabular} & \begin{tabular}{|l}
-0.18 \\
75 \\
\end{tabular} & $\begin{array}{l}0.81 \\
25 \\
\end{array}$ & \begin{tabular}{|l|}
1.3 \\
125 \\
\end{tabular} & $\begin{array}{l}\text { 0.18 } \\
75\end{array}$ & $\begin{array}{l}-1.6 \\
875 \\
\end{array}$ & $\begin{array}{l}0.31 \\
25 \\
\end{array}$ & $\begin{array}{l}-2.3 \\
125 \\
\end{array}$ & $\begin{array}{l}1.18 \\
75\end{array}$ & \begin{tabular}{|l|}
0.56 \\
25 \\
\end{tabular} & \begin{tabular}{|c|}
-0.1 \\
875
\end{tabular} & \begin{tabular}{|c|}
-0.3 \\
125 \\
\end{tabular} & $\begin{array}{l}1.43 \\
75\end{array}$ \\
\hline
\end{tabular}

As we can see from figure 2 we can take either the approximation or the details to form the features of the speech signal as illustrated in figures 3 and 4 .

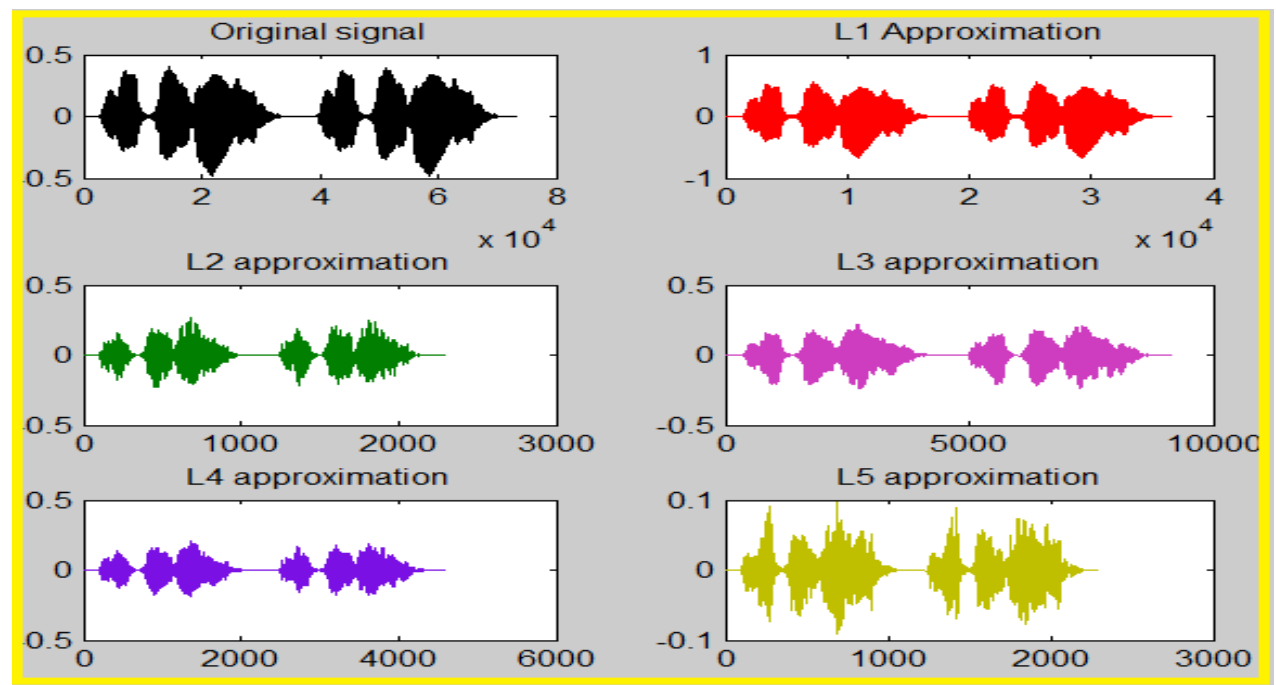

Figure 3: Approximation decomposition

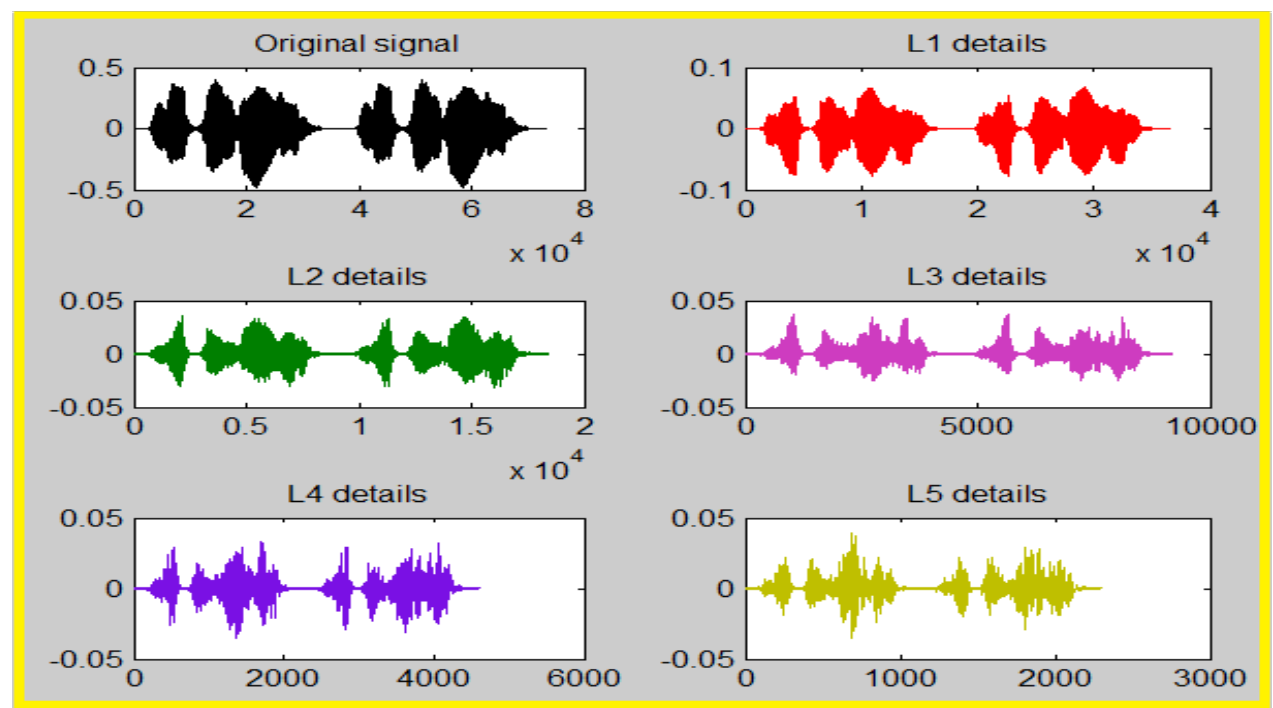

Figure 4: Details decomposition 
Vol. 9, Issue 6, June 2020

Getting the approximation or the details at any level is the process of division the previous level approximation or detail by 2, and because the speech signal size is not fix (it varies from speech signal to another) (see figures 5, and 6)we can face a problem of fixing the number of samples in each of them. So it is very difficult to obtain a fixed number of features, because it is very difficult to guess the needed number of decomposition levels, as shown in table 3 :

Table 3: Approximation values for various speeches

\begin{tabular}{|c|c|c|c|c|c|c|c|}
\hline Speech number & Levels & \multicolumn{4}{|c|}{ Level's Approximation } & \multirow{2}{*}{\multicolumn{2}{|c|}{4 elements }} \\
\hline 1 & 16 & 0.0411 & 0.1008 & 0.0600 & 0 & & \\
\hline 2 & 15 & 0.0094 & -0.0935 & 0.0723 & \multicolumn{3}{|c|}{3 elements } \\
\hline 3 & 16 & 0.0622 & 0.0976 & 0.0260 & \multicolumn{3}{|c|}{3 elements } \\
\hline 4 & 16 & 0.0141 & 0.0773 & -0.0021 & \multicolumn{3}{|c|}{3 elements } \\
\hline 5 & 16 & 0.0517 & -0.0466 & 0.0415 & 0 & \multicolumn{2}{|c|}{4 elements } \\
\hline 6 & 15 & 0.0499 & -0.0785 & 0.0586 & 0 & \multicolumn{2}{|c|}{4 elements } \\
\hline 7 & 15 & 0.0655 & -0.0523 & 0.1189 & -0.0060 & 0 & 5 elements \\
\hline 8 & 16 & 0.0713 & -0.0114 & -0.0011 & \multicolumn{3}{|c|}{3 elements } \\
\hline 9 & 15 & 0.0689 & 0.1068 & 0.0386 & 0.0144 & 0 & 5 elements \\
\hline 10 & 16 & 0.0795 & 0.0176 & 0.0256 & 0.0201 & 0 & 5 elements \\
\hline
\end{tabular}

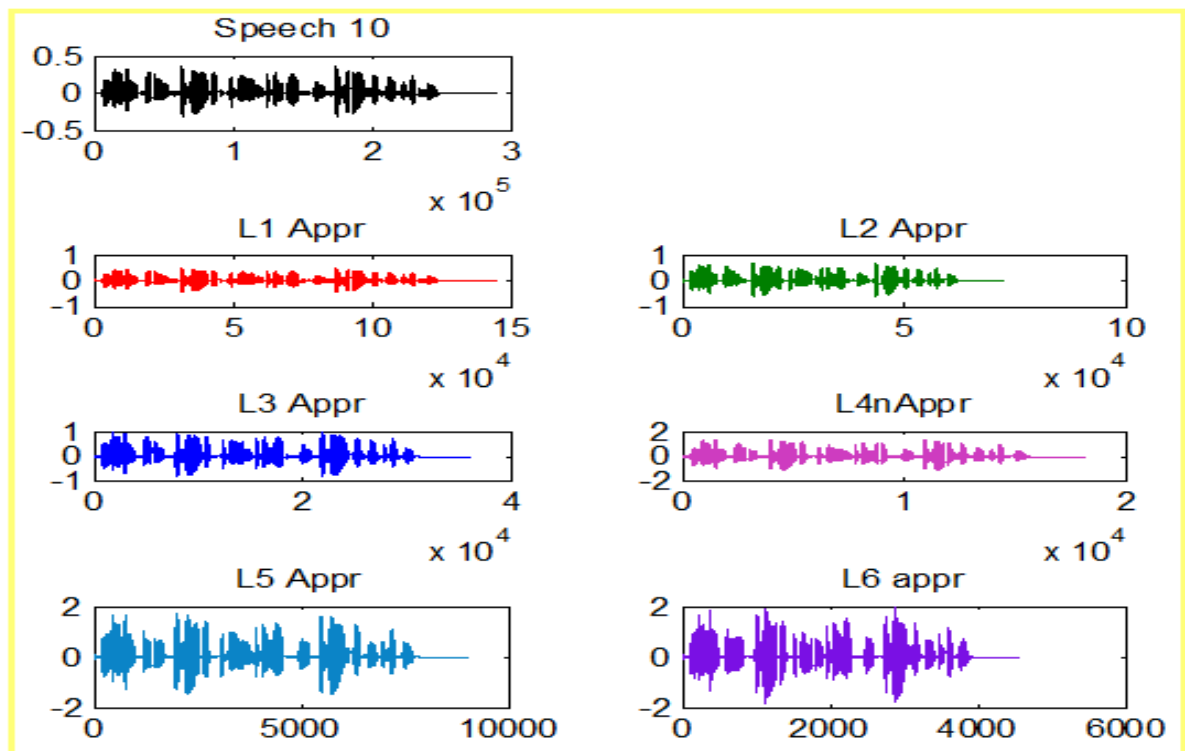

Figure 5: Using 6 level of decomposition for speech 10

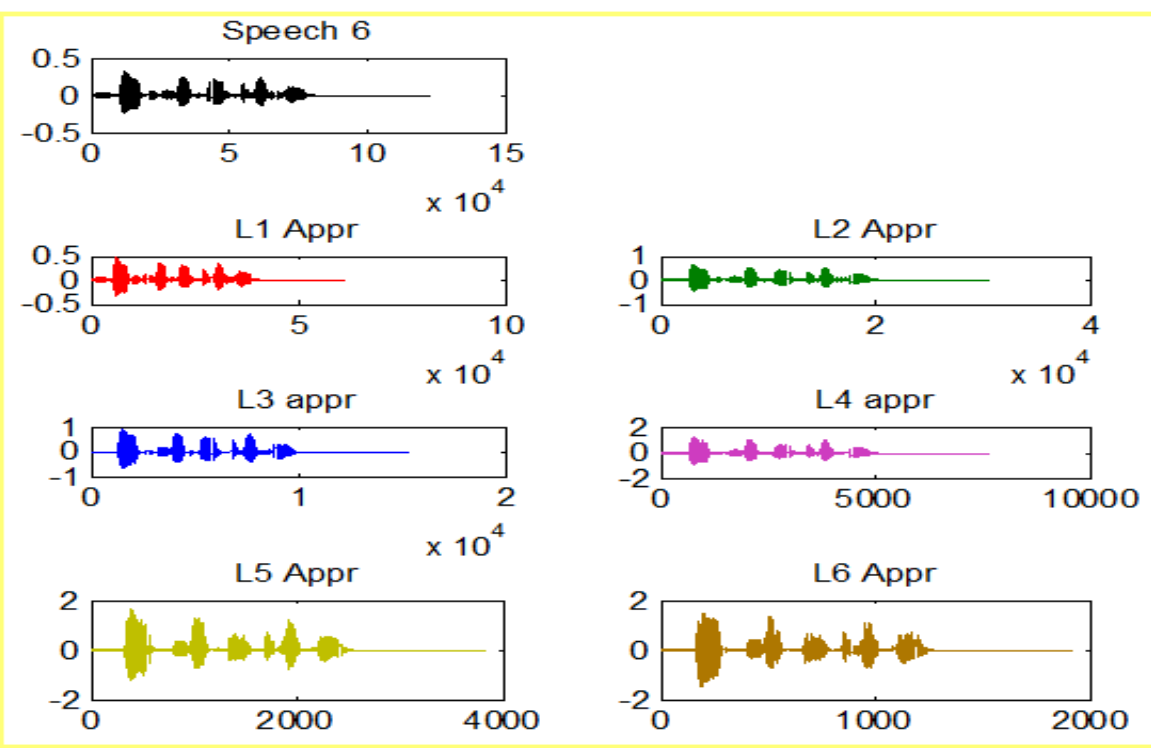

Figure 6: Using 6 level of decomposition for speech 6 
Vol. 9, Issue 6, June 2020

\section{CREATING SPEECH SIGNAL HISTOGRAM}

Histogram [14], [39], [40] is popular tool of digital image representation [29], [20], and it can gives an idea about the image features [19], [28], it is a one column matrix of 256 element [31], [32], each element points to the repetition of image intensity (between 0 and 255) [35], [36], [37]. Here we introduce a method of calculating speech signal histogram. The matrix of the discrete speech signal whether mono or stereo signal must be reshaped into one raw, then for each speech sample applying the steps shown in table 4 we can get the speech histogram.

Table 4: Speech histogram calculation

\begin{tabular}{|c|c|c|c|c|c|c|c|c|c|c|}
\hline Samples & $\mathrm{S}(\mathrm{x}-4)$ & $S(x-3)$ & $S(x-2)$ & $S(x-1)$ & $S(x)$ & $S(x+1)$ & $S(x+2)$ & $S(x+3)$ & $\mathrm{S}(\mathrm{x}+4)$ & \\
\hline Value & -1 & 0.9 & 0.3 & 0.8 & 0.5 & 0.3 & 0.9 & 0.5 & 0.7 & \\
\hline Comparison & $<$ & $>$ & $<$ & $>$ & & $<$ & $>$ & $>=$ & $>$ & \\
\hline Binary & 0 & 1 & 0 & 1 & & 0 & 1 & 1 & 1 & \\
\hline Weights & 1 & 2 & 4 & 8 & & 16 & 32 & 64 & 128 & \\
\hline Hexadecimal & 0 & 2 & 0 & 8 & & 0 & 32 & 64 & 128 & \\
\hline Summation & \multicolumn{10}{|c|}{ of 234} \\
\hline
\end{tabular}

Using speech signal histogram (see figure 7) for decomposition will control the number of elements in the approximation or the detail and here we can fix the number of features by selecting the necessary level of decomposition as we can see in figures 8 and 9.

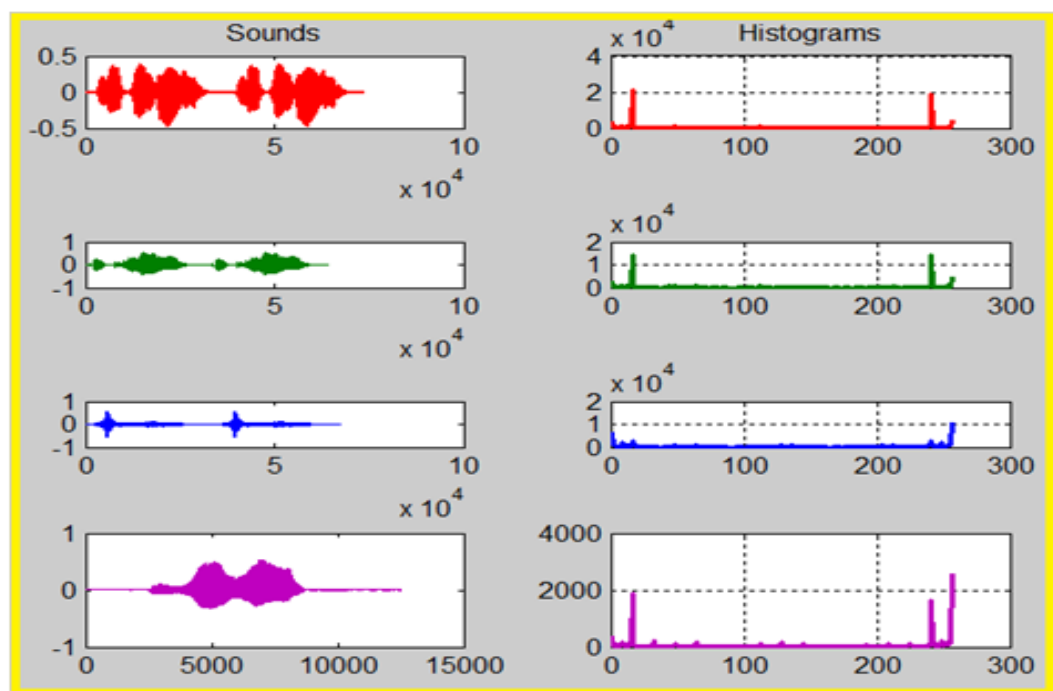

Figure 7: Samples of speech signals histogram
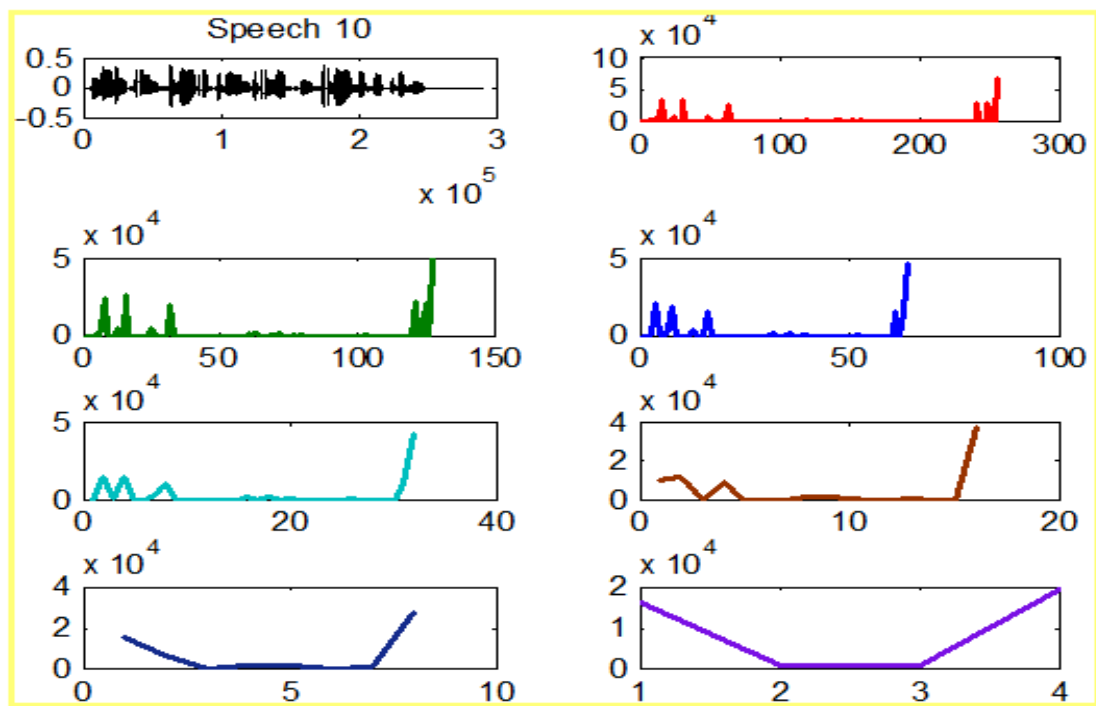

Figure 8: Speech 10 decomposition using histogram 
Vol. 9, Issue 6, June 2020
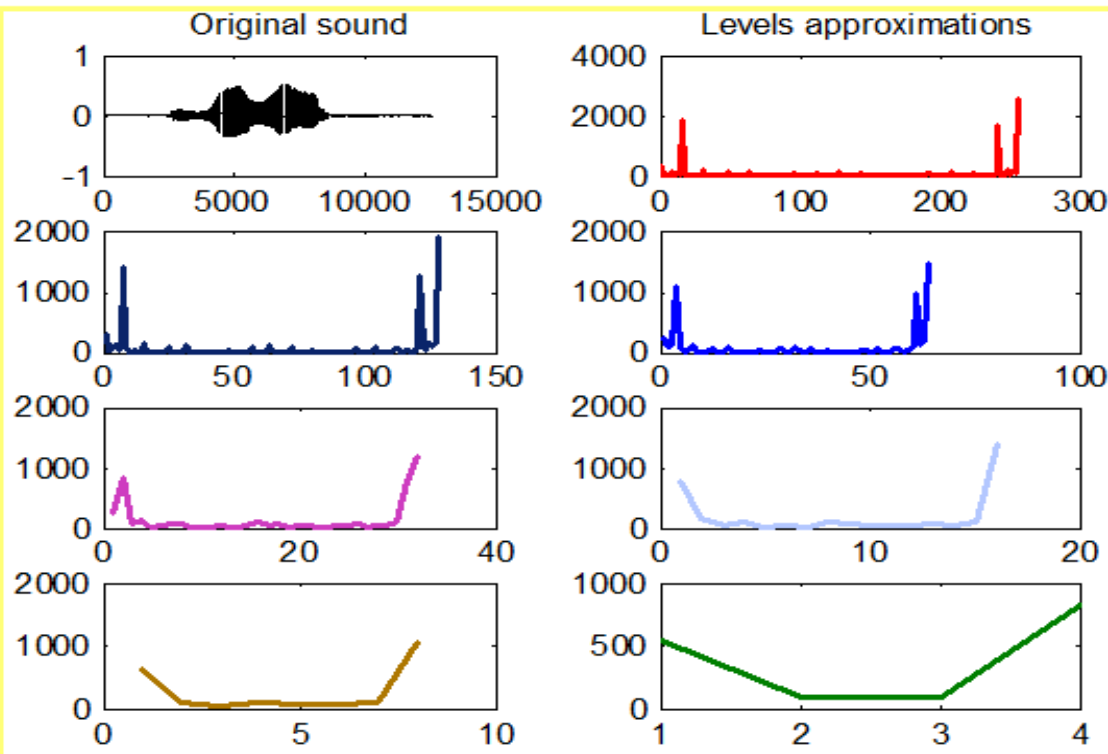

Figure 9: Speech 6 decomposition using histogram

\section{IMPLEMENTATION AND EXPERIMENTAL RESULTS}

The speech signals shown in table 1 were treated, the histogram for each signal was calculated, table 5 shows the obtained results after decomposition each speech histogram using 6 levels of decomposition:

Table 5: Experimental results

\begin{tabular}{|c|c|c|c|c|}
\hline Speech number & \multicolumn{4}{|c|}{ L6 approximation } \\
\hline 1 & 11347 & 377 & 357 & 15531 \\
\hline 2 & 5880 & 101 & 94 & 10530 \\
\hline 3 & 8783 & 332 & 314 & 13514 \\
\hline 4 & 8300 & 348 & 345 & 12890 \\
\hline 5 & 12051 & 466 & 465 & 16188 \\
\hline 6 & 48174 & 3078 & 2938 & 99563 \\
\hline 7 & 6747 & 228 & 220 & 11025 \\
\hline 8 & 8534 & 301 & 281 & 12517 \\
\hline 9 & 6930 & 224 & 202 & 11195 \\
\hline 10 & 15857 & 728 & 685 & 19186 \\
\hline
\end{tabular}

From table 5 we can see that using histogram for decomposition will overcomes the difficulties that face us in signal decomposition, here we can fix the number of features, select the number of features by selecting the number of decomposition level.

\section{CONCLUSION}

WPT decomposition is one of the best methods which can be used to extract speech signal features; this method faces some problems of fixing the number of features for each signal, and the decomposition level number because of the varying sizes of speech signals. To overcome these difficulties, we introduced a method of creating speech signal histogram, it was shown that using speech histogram in WPT decomposition will create a fix, unique features for each signal.

\section{REFERENCES}

[1] Majed O Al-Dwairi, Ziad A Alqadi, Amjad A Abujazar, Rushdi Abu Zneit, Optimized true-color image processing, World Applied Sciences Journal, vol. 8, issue 10, pp. 1175-1182, 2010.

[2] Jamil Al Azzeh, Hussein Alhatamleh, Ziad A Alqadi, Mohammad Khalil Abuzalata, Creating a Color Map to be used to Convert a Gray Image to Color Image, International Journal of Computer Applications, vol. 153, issue 2, pp. 31-34, 2016.

[3] AlQaisi Aws, AlTarawneh Mokhled, A Alqadi Ziad, A Sharadqah Ahmad, Analysis of Color Image Features Extraction using Texture Methods, TELKOMNIKA, vol. 17, issue 3, 2018.

[4] Mohammed Ashraf Al Zudool, Saleh Khawatreh, Ziad A. Alqadi, Efficient Methods used to Extract Color Image Features, IJCSMC, vol. 6, issue 12, pp. 7-14, 2017. 


\title{
International Journal of Advanced Research in Computer and Communication Engineering
}

\author{
Vol. 9, Issue 6, June 2020
}

[5] Akram A. Moustafa and Ziad A. Alqadi, Reconstructed Color Image Segmentation, Proceedings of the World Congress on Engineering and Computer Science, WCECS 2009, vol. II, 2009.

[6] Jamil al-azzeh, bilal zahran, ziad alqadi, belal ayyoub and mazen abu-zaher, a novel zero-error method to create a secret tag for an image, journal of theoretical and applied information technology, vol. 96, issue 13, pp. 4081-4091, 2018.

[7] Bilal zahran, jamil al-azzeh, ziad alqadi, mohd-ashraf alzoghoul, saleh khawatreh, a modified lbp method to extract features from color images, journal of theoretical and applied information technology, vol. 96, issue 10, pp. 3014-3024, 2018.

[8] Waheeb Abu Ulbeh, Akram Moustafa, Ziad A Alqadi, Gray image reconstruction, European Journal of Scientific Research, vol. 27, iss.2, 2009.

[9] Dr Rushdi S Abu Zneit, Dr Ziad AlQadi, Dr Mohammad Abu Zalata, A Methodology to Create a Fingerprint for RGB Color Image, IJCSMC, vol. 6, issue 1, pp. 205-212. 2017.

[10] RA Zneit, Ziad Alqadi, Dr Mohammad Abu Zalata, Procedural analysis of RGB color image objects, IJCSMC, vol. 6, issue 1, pp. 197-204, 2017. [11] Prof. Ziad Alqadi Dr. Mohammad S. Khrisat, Prof. Yousif Eltous, Dr. Saleh A. Khawatreh, Dr. Majed Omar Dwairi, Building Face Recognition System (FRS), International Journal of Computer Science and Mobile Computing, vol. 9, issue 6, pp. 15-24, 2020.

[12] Jamil Al-Azzeh Naseem Asad, Ziad Alqadi, Ismail Shayeb, Qazem Jaber, Simple Procedures to Create HSCS, International Journal of Engineering Research And Management (IJERM), vol. 7, issue 5, pp. 6-10, 2020.

[13] Amjad Y Hindi, Majed O Dwairi, Ziad A AlQadi, A Novel Technique for Data Steganography, Engineering, Technology \& Applied Science Research, vol. 9, issue 6, pp. 4942-4945, 2019.

[14] Mutaz Rasmi Abu Sara Rashad J. Rasras, Ziad A. AlQadi, A Methodology Based on Steganography and Cryptography to Protect Highly Secure Messages, Engineering, Technology \& Applied Science Research, vol. 9, issue 1, pp. 3681-3684, 2019.

[15] Dr. Amjad Hindi, Dr. Ghazi M. Qaryouti, Prof. Yousif Eltous, Prof. Mohammad Abuzalata, Prof. Ziad Alqadi, Color Image Compression using Linear Prediction Coding, International Journal of Computer Science and Mobile Computing, vol. 9, issue 2, pp. 13 - 20, 2020.

[16] Ziad Alqadi, Mohammad Abuzalata, Yousf Eltous, Ghazi M Qaryouti, Analysis of fingerprint minutiae to form fingerprint identifier, International Journal on Informatics Visualization, vol. 4, issue 1, pp. 10-15, 2020.

[17] Prof. Ziad Alqad i Prof. Yousif Eltous, Dr. Majed Omar Dwairi, Dr. Mohammad S. Khrisat, Dr. Saleh A. Khawatreh, Secure Secret Message Steganography (SSMS), International Journal of Computer Science and Mobile Computing, vol. 9, issue 6, pp. 1-9, 2020.

[18] Dr.Saleh A.Khawatreh Dr.Majed Omar Dwairi, Prof.Ziad Alqadi, Dr.Mohammad S.Khrisat, Dr.Amjad Hindi, Digital color image encryptiondecryption using segmentation \& reordering, International Jour of Latest Research in Engg \& Technology (IJLRET), vol. 6, iss 5, pp. 6-12, 2020.

[19] Prof. Ziad Alqadi Prof. Yousif Eltous, Dr. Akram Moustafa Hamarchi, Dr. Mohammad S. Khrisat, Dr. Saleh A. Khawatreh, Color Image Encryption-Decryption using RANDOM Noise and PMT, International Journal of Advanced Research in Computer and Communication Engineering, vol. 9, issue 5, pp. 1-7, 2020 .

[20] Prof.Ziad Alqadi Prof.Yousif Eltous, Dr.Akram Moustafa Hamarchi, Dr.Mohammad S.Khrisat, Dr.Saleh A.Khawatreh, Speech Signal EncryptionDecryption Using Noise Signal And Pmt, International Journal of Engineering Technology Research \& Management, vol. 4, issue 5, pp. 49-59, 2020. [21] Prof.Ziad Alqadi Dr.Saleh A.Khawatreh, Dr Mohammad S.Khrisat, Dr.Amjad Hindi, Dr.Majed Omar Dwairi, A novel method to encrypt-decrypt digital speech signal (EDDSS), International Jour of Advanced Research in Computer \& Communication Engineering, vol. 9, iss 4, pp.117-123, 2020. [22] Prof. Ziad Alqadi, Dr. Mohammad S. Khrisat, Dr. Amjad Hindi, Dr. Majed Omar Dwairi, USING SPEECH SIGNAL HISTOGRAM TO CREATE SIGNAL FEATURES, International Journal of Engineering Technology Research \& Management, vol. 4, issue 3, pp. 144-153, 2020.

[23] Dr. Amjad Hindi, Dr. Majed Omar Dwairi, Prof. Ziad Alqadi, Efficiency analysis of color image features extraction methods, International Journal of Software \& Hardware Research in Engineering, vol. 8, issue 2, pp. 58-65, 2020.

[24] Ziad A. AlQadi Amjad Y. Hindi, Majed O. Dwairi, PROCEDURES FOR SPEECH RECOGNITION USING LPC AND ANN, International Journal of Engineering Technology Research \& Management, vol. 4, issue 2, pp. 48-55, 2020.

[25] Dr. Amjad Hindi, Dr. Majed Omar Dwairi, Prof. Ziad Alqadi, Analysis of Procedures used to build an Optimal Fingerprint Recognition System, International Journal of Computer Science and Mobile Computing, vol. 9, issue 2, pp. 21 - 37, 2020.

[26] K Matrouk, A Al-Hasanat, H Alasha'ary, Z Al-Qadi, H Al-Shalabi, World Applied Sciences Journal, vol. 31, issue 10, pp. 1767-1771, 2014

[27] Jamil Al Azzeh, Ziad Alqadi, Qazem M Jabber, Statistical Analysis of Methods Used to Enhanced Color Image, XX International Scientific and Technical Conference, 2016.

[28] Prof. Yousif Eltous, Dr. Ghazi M. Qaryouti, Prof. Mohammad Abuzalata, Prof. Ziad Alqadi, Evaluation of Fuzzy and C_mean Clustering Methods used to Generate Voiceprint, IJCSMC, vol. 9, issue 1, pp. 75 -83, 2020.

[29] Dr. Amjad Hindi, Dr. Majed Omar Dwairi, Prof. Ziad Alqadi, Efficiency analysis of color image features extraction methods, iJournals: International Journal of Software \& Hardware Research in Engineering, vol. 8, issue 2, pp. 58-65, 2020.

[30] Ahmad Sharadqh Jamil Al-Azzeh, Rashad Rasras, Ziad Alqadi, Belal Ayyoub, Adaptation of matlab K-means clustering function to create Color Image Features, International Journal of Research in Advanced Engineering and Technology, vol. 5, issue 2, pp. 10-18, 2019.

[31] Ismail Shayeb, Naseem Asad, Ziad Alqadi, Qazem Jaber, Evaluation of speech signal features extraction methods, Journal of Applied Science, Engineering, Technology, and Education, vol. 2, issue 1, pp. 69-78, 2020.

[32] Ziad A AlQadi Amjad Y Hindi, O Dwairi Majed, PROCEDURES FOR SPEECH RECOGNITION USING LPC AND ANN, International Journal of Engineering Technology Research \& Management, vol. 4, issue 2, pp. 48-55, 2020.

[33] Ziad Alqad, Prof. Yousf Eltous Dr. Ghazi M. Qaryouti, Prof. Mohammad Abuzalata, Analysis of Digital Signal Features Extraction Based on LBP Operator, International Journal of Advanced Research in Computer and Communication Engineering, vol. 9, issue 1, pp. 1-7, 2020.

[34] Aws Al-Qaisi, Saleh A Khawatreh, Ahmad A Sharadqah, Ziad A Alqadi, Wave File Features Extraction Using Reduced LBP, International Journal of Electrical and Computer Engineering, vol. 8, issue 5, pp. 2780, 2018.

[35] Prof. Ziad Alqadi, Dr. Amjad Hindi, Dr. Majed Omar Dwairi, Dr. Mohammad S. Khrisat, Features Analysis of RGB Color Image based on Wavelet Packet Information, IJCSMC, vol. 9, issue 3, pp. 149 - 156, 2020.

[36] Ziad Alqadi Dr. Mohammad S. Khrisat, Dr. Amjad Hindi, Dr. Majed Omar Dwairi, VALUABLE WAVELET PACKET INFORMATION TO ANALYZE COLOR IMAGES FEATURES, International Journal of Current Advanced Research, vol. 9, issue 2, pp. 2319-6505, 2020.

[37] Amjad Hindi, Majed Omar Dwairi, Ziad Alqadi, Analysis of Digital Signals using Wavelet Packet Tree, IJCSMC, vol.9, iss 2, pp. 96-103, 2020. [38] Ismail Shayeb, Naseem Asad, Ziad Alqadi, Qazem Jaber, Evaluation of speech signal features extraction methods, Journal of Applied Science, Engineering, Technology, and Education, vol. 2, issue 1, pp. 69-78, 2020.

[39] Ziad A AlQadi Amjad Y Hindi, O Dwairi Majed, PROCEDURES FOR SPEECH RECOGNITION USING LPC AND ANN, International Journal of Engineering Technology Research \& Management, vol. 4, issue 2, pp. 48-55, 2020.

[40] Amjad Y Hindi, Majed O Dwairi, Ziad A AlQadi, Creating Human Speech Identifier using WPT, International Journal of Computer Science and Mobile Computing, vol. 9, issue 2, pp. 117-123, 2020.

[41] Prof. Ziad Alqadi Prof. Yousif Eltous, Dr. Akram Moustafa Hamarchi, Dr. Mohammad S. Khrisat, Dr. Saleh A. Khawatreh, SPEECH SIGNAL ENCRYPTION-DECRYPTION USING NOISE SIGNAL AND PMT, International Journal of Engineering Technology Research \& Management, vol. 4, issue 5, pp. 49-59, 2020. 